\title{
Strategies to Ensure the Effective Implementation of Learner Discipline Policies: A Case of 4 South African Secondary Schools
}

\author{
Bilatyi Nkosana \\ Rembe Symphorosa \\ Shumba Jenny \\ School of Further and Continuing Education; University of Fort Hare \\ jennymshumba@gmail.com
}

Doi:10.5901/mjss.2014.v5n23p1578

\begin{abstract}
The study examined the implementation of learner discipline policies in four secondary schools in the Graaff Reinet district. It is located in the interpretivist paradigm and employed the triangulation design to collect data. Four schools and participants in the study were purposively sampled. Semi-structured interviews and focus group discussions were the main instruments used for data collection. Data revealed that although schools used different strategies to implement learner discipline policies, such as, Code of Conduct, Disciplinary hearing, Safety and Security Committee, Educators, Corporal Punishment, Alternative methods to Corporal Punishment, there were a number of limitations in implementing policies to maintain learner discipline. To address disciplinary problems, the study has the following key recommendations Policies should be crafted by all stakeholders for ownership and there should be collaboration in implementation of those policies.. The Code of Conduct should be issued to all learners at the school at the beginning of the year in the language of preference, with school rules. Educators should engage the Department of Education to conduct workshops in building capacity of educators to maintain learner discipline. Schools should establish partnerships with other sister Departments such as SAPS, Social Development, Correctional Services, Health to, maintain learner discipline.
\end{abstract}

Keywords: Learner discipline, Effective implementation, Code of Conduct, Corporal Punishment

\section{Introduction}

Learner discipline constitutes a necessary aspect for effective learning in schools worldwide, including South Africa. According to Wolhuter and Steyn (2003:521) discipline at schools has two very important goals, namely to ensure the safety of staff and learners, and to create an environment conducive to learning and teaching. Joubert, De Waal and Rossouw (2004:77) argue that "if learners are too scared to attend school because they are constantly threatened or when the behaviour of other learners in a school disrupts the normal teaching and learning process, this has a serious impact on learner's access to equal educational opportunities".

The advent of democracy resulted in a new constitutional and legislative framework as well as new policies which had implications for how schools should discipline learners. According to Section 12(1) of the Constitution (Republic of South Africa (RSA), 1996a), no person shall be subjected to torture of any kind, nor shall any person be treated or punished in a cruel, inhuman or degrading way. In the context of the school this implies that the education environment should be conducive, there should be security to property and equipment, there should be clean toilets, no harassment when learners are attending classes, writing tests and examinations, (Republic of South Africa (RSA), 1998).

After 1994 the democratic government of South Africa abolished inhumane and punitive learner discipline policies which were enforced by the Apartheid Government. New constitutional and legislative framework and policies which had implications on how schools should maintain learner discipline were put in place (RSA, Constitution Act No.84 1996; Prinslo0, 2006; Joubert, de Waal, and Rossouw, 2004; Hammert, 2008). The provisions were outlined in the Constitution and other policies among them SASA (RSA, 1996; Hammert, 2008; Joubert, 2008). SASA provided for the establishment of code of conduct in all schools. It outlawed corporal punishment and suggested alternative forms of punishment (RSA, 1996).

All learner discipline policies are currently being implemented in schools (Hammert, 2008; Joubert, 2008). However, despite the implementation of the policies, the incidents of ill-discipline in schools have been on the increase. 
This is evident from the incidents of violence and other disciplinary problems in schools reported by the media and other stakeholders (Roos, 2003; Prinsloo, 2006; Joubert, de Waal, and Rossouw, 2004; Hammert, 2008; Joubert, 2008; Squelch, 2000). The Daily Despatch of Wednesday 10 October 2012 also reported in an article "Teachers bemoan bad behaviour" that teacher's and learners' lives were in danger from boys smoking dagga in toilets, abusing drugs and alcohol, and from bullies who bunk classes, roaming around the school grounds. Despite all the regulations and policy documents there seems to be an increase in cases of indiscipline in schools. Hence, this study examined the implementation of learner discipline policies in four secondary schools in the Graaff Reinet district. The key question is: How are learner discipline policies implemented in four secondary schools in Graaff Reinet district?

\section{Methodology}

\subsection{Research Paradigm}

The study adopted the interpretive paradigm because it brings out the views and experiences of educators, learners and parents about learner discipline. In this perspective the researchers solicited the responses of the respondents within their context. The researcher also took cognizance of the fact that those involved, that is, the research participants are in the best position to describe their own situation (Guba \& Lincoln in Maree, 2007; Mertens, 2010). The researchers' stance in choosing this paradigm follows the assertion that Interpretivists believe that human life can only be understood from within and cannot be observed externally (Livesey, 2006).

\section{Research Design}

In this study a case study design was adopted. According to Rule and John (2011:3), a case may be a person, a classroom, a programme, an institution or a country. A case study tends to be concerned with investigating many, if not all variables in a single unit and seeks to understand individuals' perceptions of events (Cohen, et al., 2006; Merriam, 1984; Yin, 2003). In this study the selected cases are the four secondary schools in the Graaff Reinet district.

\section{Sampling and Sample}

Sampling is the process of finding people or places to study; to gain access to study; and to establish a rapport so that participants provide relevant data (Creswell 1998). In this study, purposive sampling was utilised where the researcher handpicked respondents on the basis of his judgement of their typicality (Cohen et al., 2006). The purposive sampling technique involves selecting certain units or cases "based on a specific purpose rather than randomly" (Tashakkori and Teddlie, 2003a:713). The selected sample included 4 Principals, 2 Deputy Principals, 4 HODs, 5 senior educators and 5 SGB members.

\section{Data Collection Instruments}

The researchers solicited data through interviews, focus groups and analysis of documents to assess the implementation of learner discipline policy. Face-to-face semi-structured interviews were administered to 4 Principals, 2 Deputy Principals, 4 HODs, 5 senior educators and 5 SGB members. The primary documents to be analysed by the researchers included the parents' minute book from 2010 up to 2012 and policies formulated during the period regarding learner disciplinary problems and strategies that the schools have used to discipline learners. The main aim for collecting these documents was to find out whether the schools had put in place any policies regarding learner disciplinary action.

\section{Data analysis}

The data from the various sources was transcribed, reviewed and analysed using the thematic method. This involved a process of identifying recurrent themes across the transcripts.

\section{Trustworthiness}

Trustworthiness consists of four criteria namely credibility, meaning the relationship between the findings and collected data; transferability, whether findings can justifiably be transferred to other contexts; dependability, is the assurance to 
the people about the findings from the raw social context; and conformability, ensuring the public that actions were appropriate and without bias (Lee \& Lings, 2008). Trustworthiness in this study was ensured through member checking.

\section{Findings}

The data gathered showed that schools used different strategies to ensure effective implementation of policies that enhance discipline. This section presents data collected on the strategies and how they were implemented in schools.

\subsection{The Code of Conduct}

All the participants consented that their schools had Codes of Conduct. They also stated that they were developed in a participatory manner as members (SMTs, SGBs, Educators, learners, parents, HODs and Principals) of the school community were involved in their formulation. This was confirmed by the following respondents:

\section{P1. Disclosed:}

The school does have the Code of Conduct. Stakeholders that participated in crafting are; the SGB, SMT and the RCL. Each stakeholder would discuss the rules and present them in a plenary session. During the formulation the buying in of stakeholders is of importance because we have to own it. Teachers monitor the implementation of the Code of Conduct by enforcing the rules through detention, extra work, cleaning of the school yard. These punishments are only administered in cases of minor misconducts.

This was also confirmed by HOD1 from the same school that:

The Code of Conduct is in place, it was developed years ago but it has not been revised. The SMT and some Post Level educators developed the Code of Conduct. Not all stakeholders participated in the formulation of the Code of Conduct. To implement the Code of Conduct stakeholders, RCL, SMT and SGB members at the school do the monitoring of detention classes, when children are given extra work after school.

However, P3 disclosed that although they had the Code of conduct, it was developed by one individual:

We do have the Code of Conduct which was developed by Mr. Coetzee (pseudonym) an ex-teacher at the school. No role was played by the stakeholders. We implement it by talking to the learners to obey the rules, observe punctuality at school, do their work, wear school uniform and be always being obedient to teachers.

The respondents also cited a number of challenges that were encountered in crafting the code of conduct such as wastage of time, financial constraints, inconsistency, no sustainability. These are summed up in the following captions:

P3 intimated:

Crafting of school plans and policies takes almost half of the school day. It is better for the Code of Conduct to be crafted by an experienced person.

P4 also pointed out:

Each stakeholder had discussions guided by the South African Schools Administration and Management System (SASAMS) to come up with a comprehensive Code of Conduct. To implement the Code of Conduct is difficult because some learners ignore it. Financial constraints do not allow certain things to happen at the school e.g. issuing the Code of Conduct in the language of preference to every learner; discuss it with the parent of every learner who is admitted each academic year.

Dep P2 pointed:

...There are problems in the implementation Of the Code of Conduct at the school. The biggest challenge is inconsistency and no sustainability in the implementation of the Code of Conduct.

Snr Educ 3 disclosed:

It is difficult to implement at the moment, most of the teachers do not have a copy, learners do not have copies either although it was agreed at registration that each learner should get the copy of the Code of Conduct. Financial 
constraints make it difficult to duplicate the document.

P5 indicated that he had never seen a Code of Conduct. This was confirmed by the following parents.

Parent 2 stated:

Lack of interest in education among the community as most parents are working in cities like Port Elizabeth and Cape Town and leave children under the care of grandparents and other relatives. The grandparents and guardians cite matters like age, health problems; those who are working as domestic workers knock off at work very late. Therefore it is difficult to go and attend the disciplinary problems that might have arisen from their children's behaviour.

Parent 4 disclosed:

...At the moment it is difficult to implement the Code of Conduct and not everybody does have a copy. Financial difficulties do not allow us to duplicate it for everybody.

Parent 5 disclosed:

I have never seen the Code of Conduct in this school, maybe it's there, but I never saw it. As far as I know there is no Code of Conduct in the school.

FG4 disclosed:

Some classes have the code of conduct but the majority of learners do not have the Code of Conduct. Miss Velile (not real name) developed the Code of Conduct. There were no other stakeholders when it was formulated.

It is evident that generally schools possess Code of Conducts although the involvement of all stakeholders is questionable from learners' points of view. The implementation is also mired by many challenges.

\subsection{Alternative strategies used by school instead of corporal punishment}

The SMTs were asked about the alternative methods that were used in place of corporal punishment to maintain discipline in the schools and the problems encountered in their use. Principals, HODs, Educators, Parents and learners cited detention, consultation with parents and cleaning of toilets, classrooms and school premises as well as verbal warnings as the most common alternatives. This was confirmed by various participants as shown below.

P1stated:

The alternatives to corporal punishment were detention which was administered after school on the same day as the offence was. It was found out that schools employ different strategies, which among many, involve counselling and advice from different stakeholders

The participant further remarked that, one of the barriers to implement alternatives to corporal punishment was:

At the end of the school day, names of learners who had transgressed are announced through the intercom to remind them about the detention classes but surprisingly, some learners would not turn up. Even if they all come, there is no change; learners do not change their attitude. Therefore detention, as far as I am concerned, does not work as a deterrent.

P2: pointed:

The best alternative method to corporal punishment is to send the learner home to fetch the parent. Detention was another alternative that is used in place of corporal punishment. The two methods so far have worked for the school because the level of minor misconducts has dropped drastically.

Dep P1 mentioned that verbal warnings were being given to learners, sometimes as an alternative method to corporal punishment. HOD3 said:

We talk to the learners. There is no detention as an alternative method to corporal punishment because detention drains the energy of educators. 
It also surfaced from learners that corporal punishment was administered by educators although it is illegal. HOD 4 stated:

We administer Corporal Punishment but not much. We have an agreement with the RCL that if a learner transgresses. he/she should be given 2 lashes

P4: The Principal of S4 disclosed confidently that the school administered corporal punishment. He stated that:

At the school we deal with learners who still need to be shown the way. We have an understanding with the parents that it should be administered. Learners are also aware that it is illegal but at least two lashes are administered. Besides that, learners' clean toilets and It was found out that schools employ different strategies, which among many, involve counselling and advice from different stakeholders.

It was found out that schools employed different strategies, which among many, involve counselling and advice from different stakeholders. It also surfaced from learners that corporal punishment is administered by educators although it is illegal. There were mixed feelings on the effectiveness of strategies from learners as some of them said the strategies put in place were not effective even the use of corporal punishment while others found that detention and corporal punishment were the most effective strategies.

Educators however, indicated otherwise probably to safeguard their jobs.

Snr Educator 1 intoned that:

No Corporal punishment is administered in the school, we always adhere to SASA principles that learner's rights must be observed. The alternative methods include detention if the learners commit an act of minor misconduct; they are given a verbal warning. If he or she does the same misconduct $\mathrm{He} / \mathrm{sh}$ is referred to the Grade Head. The third and fourth time, the parent is called then the Disciplinary Committee, but the Disciplinary Committees the last resort.

The parents were asked whether some of the educators were still administering Corporal Punishment and what alternatives methods to Corporal Punishment were used by the school.Parents indicated that Corporal Punishment was not administered at school. Alternative methods to Corporal Punishment mentioned were detention, verbal warning, and calling the parent of the learner to school. This was confirmed by the following parent.

Parent 2 disclosed:

As far as I know, no teacher administers Corporal Punishment. The alternative methods are detention and suspension of the learner for a week.

In contrast, Parent 4 remarked that they administer Corporal Punishment.

We use sticks and lashes are inflicted to the back when it is a boy. Pinching is also used because the learners do not behave well. The Principal sends the learner home with a letter inviting his/her parent to the school.

Learners were asked to state their views on the administering of Corporal Punishment and to state their views on the alternative methods to Corporal Punishment.

FG1: The learners disclosed collectively that it is right to administer corporal punishment in the school because there are situations where some learners come to the school drunk. However, some educators misused it. They went on to state that administering Corporal Punishment did not help because learners misbehaved more. Some learners just walked out of classes when there was an argument with a teacher.

FG2 remarked that Corporal Punishment was still administered at the school. They felt that the alternatives to Corporal Punishment were not effective because learners kept on transgressing the rules. These were the learners that must accept Corporal Punishment. They strongly felt that teachers must be serious in implementing detention because it works. Children were scared to be sent on detention.

FG3 in concurrence with FG2 indicated that some educators still administered Corporal Punishment at the school to enforce discipline especially in Grade 8, to deal with those learners that did not want to listen. The learners stated that alternative methods to Corporal Punishment, such as, sending of learners out of classrooms did not help because the learner did not learn anything. They just get time for a smoke break.

FG4 disclosed:

Some educators are still administering Corporal Punishment. However, the alternative methods of cleaning toilets are 
harmful to the health of the learners because they can contract diseases from the toilets. It is not the learners' duty to clean the toilets. We do not have problems with the cleaning of classrooms and the administration block. The alternative methods do not work because learners come late to school and they do not do their homework.

There were mixed reaction as to the administering of Corporal Punishment because some educators and parents admitted that it was still administered. Generally it was evident that some schools (educators) were still administering Corporal Punishment although it had been banned, the majority of learners indicated that Corporal Punishment was administered by teachers in school and they had nothing against it and felt that the alternatives to Corporal Punishment were not effective and some were a health hazard. The Disciplinary hearing was one strategy that was common in the four schools in an effort of ensuring effective discipline.

\subsection{Disciplinary Hearings}

The views of Principals and senior educators were sought on disciplinary procedures as they (Principals and senior educators) were involved in the day to day running of school and they were always in contact with the learners. They all concurred on the procedures followed as witnessed by some responses and showed knowledge of statutory instruments.

$\mathrm{P} 1$, in connection with the above question said:

The Disciplinary Committee is the last resort at the school but firstly we invite the parent of the learner who has misbehaved. The Disciplinary Committee is called; the chairperson of the Disciplinary Committee is a parent who leads the meeting. The Principal and the educator give evidence. The Principal acts as an overseer of the whole process and acts as a neutral person. The process is given a chance to unfold and the learner is excused when the final decision is to be taken by the Disciplinary Committee. The Education Development Officer (EDO) is informed about the process and the outcome if a learner has been suspended for a week. Records are kept in the Principal's office

The statement indicated the fair process that is followed by the school to discipline a learner who had transgressed. The aim was not to punish or embarrass the learner but the learner must be able to take punishment for his/her actions. The EDO also was informed about the process and upon the suspension of a learner.

P2 outlined the options as:

Option (1):

An action of suspending the learner and giving the parent the responsibility of monitoring the child to change the behaviour or the responsibility of ensuring that he/she catches up with the work that has been done Option (2) Suspend the learner from the school with no role played by the parent and to help the learner catch up when he is finished with the sentence. The Principal has the final say in the Disciplinary hearing. Upon the finalization of the case the Disciplinary Committee keeps the records, the EDO is furnished with the minutes but so far in 2012 there has been no hearing.

\section{P4. Also pointed out:}

'The educator deals with the problem. He/she reports to the class teacher and the HOD deals with the problem. The HOD investigates, calls the Principal and the SMT. The SMT refers the case to the Disciplinary Committee. The Disciplinary Committee calls the SGB, The parent of the learner is also called in writing. The case is discussed and the Disciplinary Committee makes recommendation to the SGB. The SGB takes the final decision. Records are kept by each teacher with the signature of the parent and the learner. The records are kept for the purpose of reference. The Disciplinary Committee keeps records also.

The statement was similar to the others but with P1, P3 the Grade Head /subject educator plays a role as the investigation officers whereas in S4 the HOD deals with the problem. It was not clear whether at the school the system of Grade Heads and Phase heads was followed. The statement is similar to P2 where the final decision is taken by the SGB but P1 and P3 have stated that the Disciplinary Committee takes the final decision

Dep P2. Asserted:

Outlined the options as:

Option (1):

An action of suspending the learner and giving the parent responsibility of monitoring the child to change the behavior or the responsibility of ensuring that he/she catches with the work that has been done or 
Option (2) outlined: to suspend the learner outside the school with no role played by the parent, to catch up when he is finished with the sentence. The Principal has the final say in the Disciplinary hearing. Upon the finalization of the case the Disciplinary Committee keeps the records, the EDO is furnished with the minutes but so far in 2012 there has been no hearing.

The statement indicated the fairness in the whole process of the Disciplinary hearing. The learner was also catered for in the process. The aim of the Disciplinary Committee was for the learners to learn a lesson. The statement concurred with that of Dep1, P3 where the Disciplinary Committee made the final decision.

HOD4 Asserted:

The educator deals with the problem. The educator reports to the class teacher who reports to the HOD, the HOD deals with the problem, investigates it and then calls the Principal and the SMT. the SMT refers the case to the Disciplinary Committee. The Disciplinary Committee calls the SGB. It is the SGB that will invite the parent in writing.Discussions will continue and the final verdict is taken. The Disciplinary Committee makes recommendations to the SGB to take a final decision. Records are kept by the teacher. After the final verdict has been taken both the parent and the learner should sign admission of guilt of the learner. Record keeping is useful for the purpose of references. The Disciplinary Committee keeps the records of serious cases.

The statement indicated how serious educators were in maintaining learner discipline. Every educator who teaches the child had a role to play. It indicated that educators were a united front in curbing learner indiscipline. The parents were not left behind but were also informed of the role they should play in the education of the learner. The statement is similar to the statement of P4, the Disciplinary Committee had all the powers but the SGB took the final decision.

Senior Educ 4 also said:

Step (1) the hearing at the school is held after the educators have tried to talk to the learner. Serious cases are reported to the Principal by the educator. A letter is written to the parent informing him/her about the date of the disciplinary hearing

Step (2) on the date of the hearing discussions take place but if the matter is too serious e.g. stabbing another learner, the police are called.

Step (3) The SGB and the Disciplinary Committee take the final decision in matters that include continuous bunking of classes, continued truancy, not doing homework, disrespecting educators. Throughout the process records are kept in the Principal's office in the strong room.

The statement indicated that educators at the school had a dual role to play. A learner's case was referred to the Disciplinary Committee only to show how serious the educators were to change the attitude of the learner. The statement agreed with the statements of P1, P3 and HOD 3 that the Disciplinary Committee was the last resort to try and find a corrective measure. The statement also concurred with P3 and HOD 3 who are the only participants who had indicated that police were involved when a learner was stabbed to death in the school premises. It indicated how determined the school authorities were in instilling learner discipline.

Data had revealed that Principals, Deputy Principals and educators were well versed in disciplinary procedures as stipulated in policy documents and all stakeholders were involved in disciplinary cases.

The views of parents were sought on disciplinary procedures to find out whether cases concerning discipline were correctly handled and also whether learners' views were sought on the issues since they are the offenders.

Parent 1 disclosed:

As the new SGB, we have not experienced cases of a serious nature that warrant a sitting of the Disciplinary Committee, but if there are cases of this nature, parents will be informed. The SGB has the power to take serious decisions in handling disciplinary cases.

The statement indicated that the new SGB have not dealt with serious cases yet but other cases were resolved internally by the educators and the SMT, the cases that have happened so far did not need the involvement of the SGB.

Parent 2 also disclosed and added

There have been no disciplinary cases that have been reported to us by the management of the school

The statement was similar to the one of Parent 1 because the SGB is only 4 months old.

Parent 3 remarked: 
If the learner is accused of serious misconduct the matter is referred to the Disciplinary Committee. The parent is called. On the arrival of the parent the next day they discuss the issue with the parent and the learner. The SMT, SGB and the Disciplinary Committee make the final decision. Parents of the learner would agree to the decision. Records are kept in the Principal's office.

The statement was indicative of the parental role the Disciplinary Committee of the school plays, how lenient and transparent they were in the process. The aim of the Disciplinary Committee was to correct the misconduct of the learner, rather than to punish the learner. The statement was similar to the statement of P3, HOD3, Senior Educator 3 who had outlined the same processes that were followed by the school when serious disciplinary cases were handled.

Parent 5 remarked:

The child is sent to the Principal after the class educator has discovered that the child has committed a serious act of misconduct. He /She is sent home and the parent is called in writing setting a date for the disciplinary hearing. An incident happened at the school where the cottage was vandalized during holidays. The parent was called but the parent sided with the children. The matter was referred to the police. Two boys quarrelled in class in March 2012. One went home to fetch a knife. It was difficult to stop him so the police were called. The Disciplinary Committee recommends to the SGB to take a final decision.

The statement indicated the dangerous conditions under which educators and parents worked. Parents were similar to educators because educators had to play the role of parents but conditions where they had to dispose learners who were carrying dangerous weapons put their lives at a risk. The statement concurred with the statement of Senior Educ 4 that stated that the police were called if it came to a push.

It had come to light that in some schools there were no serious disciplinary cases as indicated by parents. Generally, parents seemed to be aware of disciplinary procedures and this indicates that correct measures are adhered to in dealing with disciplinary cases.

Learners were asked to give their views on what happens at disciplinary hearings and what role, if any, do they play, what changes they would like to see in the process and how does the Disciplinary Committee arrive at the final verdict.

FG1 disclosed:

A letter is sent to parents. We have never been involved in any hearing only the SMT and the Principal know what happens. We would like to see the RCL being part of the hearings for learners to receive a fair hearing.

The statement contrasted the statement of P1, Dep P1, and HOD1 Senior Educ 1 that learners were part of the hearing.

FG2 collectively agreed:

At the school, there was an incident where a boy threatened to stab the Principal. and the police were called. Parents of the learner were also called to attend the disciplinary hearing. The RCL did not play any role because they were not invited. We would like to see the RCL representing the learners, parents should be allowed to hire a lawyer to defend the child not to victimized

The statement indicated that the RCL did not play any role at the school in the disciplinary hearing which was stipulated in SASA regulations

FG3 remarked by stating:

In the case of misconduct the case is sent to the Principal to decide whether it is a case of Disciplinary Committee or it should be handled internally. If it is a serious case a date is set for the child to appear before the Disciplinary Committee. A letter is sent to the parent to accompany the learner. A letter is sent to the SGB members. The RCL have to be present to ensure that the child is given a fair hearing. When the hearing is over, the parent and the learner are sent outside for the Disciplinary Committee and the SGB to come to a final decision. We would like to see changes such as, if the child is accused of serious misconduct, there should be a representative from the RCL. The parent of the child should be part of the decision making, but should not be asked to step outside when the final decision is taken.

The statement indicated that the learner's rights and the parent's rights were not mentioned in the process of dealing with the cases of serious acts of misconduct. It appeared that the Principal had a big influence when the final decision had to be taken although the Disciplinary Committee handled the serious cases of learner discipline. The final decisions that were taken were pre determined decisions. The RCL's powers during the Disciplinary hearing were limited; 
they were not allowed to cross examine either the victim or the defendant.

FG4 stated:

\begin{abstract}
If learners fight, they are sent to the Principal. The Principal calls the parents of the two learners in writing informing them about the date of the disciplinary hearing.

At the hearing the learner who started the fight will be asked to plead guilty or not guilty by the Disciplinary Committee If he/she pleads guilty a decision is made by the Principal. If the learner has pleaded not guilty, the class teacher gives evidence, questions are asked of the learner.

Learners do not play any role. We would like the Disciplinary Committee to play a role so that there is reconciliation between the two learners rather to find one guilty. The learner who is found guilty should be made to apologize in-front of other learners. To extend the Disciplinary Committee, we would like the class representatives to be part of the hearing because they are usually eye-witnesses. The RCL does not play a role in the Disciplinary Committee.
\end{abstract}

Concerning the issues of the disciplinary hearing it was evident that the learner's rights and the parent's rights were not mentioned in the process of dealing with the cases of serious acts of misconduct. Again it appears even in S4 that the Principal is having a big influence when the final decision is to be taken; the Disciplinary Committee is just echoing what the Principal and the SMT have already decided. The final decisions that are taken are predetermined decisions. The RCL does not have any power as the learner representative during the Disciplinary hearing.

The responses from learners showed some maturity and understanding of disciplinary procedures to be followed. However, there are mixed reactions on involvement of RCL as some respondents indicated that RCL are not invited in some schools.

\title{
8.4 Safety and Security Committee
}

The researcher sought the views of the SMTs on whether the schools had Safety and Security Committees and how the committee applied the principles of safety to ensure the safety of learners and educators. It was revealed that most schools had no Safety and Security Committees.

P1. Disclosed his point of view:

To be honest we do not have Safety and Security Committees. The Committee was supposed to have been established a long time ago after so many incidents happened at the school. The most recent incident was on 06 May 2012 when two boys who were both carrying knives fought, and stabbed each other. No educator wanted to intervene because we were scared. There has been no random searching at the school so far. It is high time that the Safety and Security Committee was established.

\section{P2 asserted:}

We have a school grounds plan to ensure the safety of our learners. The problem is that we do not have proper fences. There is an invigilation time table to manage the learners the whole year because we are not sure when something unexpected will happen at the school. To ensure safety, the school gates are closed. There are groups of educators Teams A, B and C. Teachers are deployed to watch what is happening at the learner's toilets and playgrounds. We do random searching for drugs dangerous weapons and the police help us

The statement indicated how conscious the educators are about the safety of the learners because at the back of their mind they were aware that parents put their trust in them for their children's safety.

P3 disclosed:

At the moment it is not in place, it will be put in place by the new SGB. It is difficult to enforce something that was working for the school to new People; they have to be orientated first. We do random searching with the help of the SAPS; there have been two random searches in 2012

The statement indicated that although the Safety and Security Committee has not been established, it is in the pipeline because they know that children's safety is a concern in the school after the incident in 2010. The statement concurred with the statements of P1, P2 that security in schools must be beefed up.

P4.also said:

It is there but it is dysfunctional. We apply the principles of safety by doing random searches there have been two 
random searches in 2012 by the SAPS upon suspicion of smoking of dagga. After $08 h 10$ the gates at the school are locked for security reasons.

The statement concurred with the statement of P3 that random searches have to be done at school. There have been two random searches at the school but with S4, it only happens when they are suspicious of something but in S3 it is carried out anytime.

Dep P2 Disclosed:

\begin{abstract}
Yes, there is a Safety and Security Committee which is entrusted arches with ground duties upon the start of the school, to manage late coming, monitor learners during breaks in the playground, during change of periods and in class generally. There are groups $A, B$ and $C$. during the change of period the class representatives, one leads and the other at the back of the class. Random searching is done in every term.
\end{abstract}

The statement concurred with the statement of P2 that there was a ground plan to ensure the safety of the learners, educators were alternating the duties. It is indicative of the knowledge of administration and the SMTs upheld the principles of the SASA document.

HOD2 in connection with the above question remarked:

\begin{abstract}
No there is no Safety and Security Committee at the school but we have a safety policy which is related to the policy of the police forum. We randomly search for weapons and drugs like dagga with the help of the police.
\end{abstract}

The statement differed to the statement by P2, Dep P2 that a safety committee is in existence in the school. These were members of the SMT who were supposed to be complementing one another and be knowledgeable about what is happening in and around the school. They agreed that random searching was done but the participant has not allocated time specifics as to when it was done.

HOD 3 asserted:

There is a Safety and Security Committee that looks on safety issues by ensuring that visitors who enter the school report at the secretary's office. Random searching is done where there are emergency cases at the school.

HOD 4 agreed with the statement of P4 that there was a Safety and Security committee but it was dysfunctional. Parents were not visible. They further concurred that random searching sometimes happened with the help of the police in search of dangerous weapons and drugs.

There were mixed reactions from participants on the availability of Safety and Security Committee in schools as some schools had none and some were dysfunctional. In other schools they were non-existent.

\title{
9. Discussion
}

Despite of the existence of the school code of conduct, most schools in the studied area continued to experience student discipline problems but nonetheless schools continue to use it. The results from the study are in line with the findings of Stevens et al,(2001) that the Code of Conduct would not reduce the incidence of violence and injury, but together with other environmental, educative and structural strategies they may create a context in which behavioural expectations are consistently and fairly applied (Stevens et.al 2001). Sushila (2004) concedes that, punishment is often repeated without ever producing the desired result; that of correction and a change of heart in the students.

The study revealed that the drafting of Code of Conduct was affected by illiteracy of some parents as they failed to understand certain issues. This in line with the weaknesses that are outlined in the Bottom Up approach. The behaviour of street level bureaucrats is also criticized as they usually overestimate the use of their discretion and overemphasize their autonomy versus top officials (Pulzl and Treib, 2007). The actions of the street bureaucrats are likely to disadvantage people with very little education and poor social background are less likely to benefit as they may not fully comprehend the meaning of the policies while the more educated elite are likely to benefit from the social services (Paudal, 2009).

The research study revealed that learners in some schools were suspended; some were expelled without the knowledge of the HOD this was contrary to the procedures that are stipulated by DoE (2000) and SASA (1996) which state that the HOD is in change and of suspensions and expulsions. This was an indication that policy decisions made by the elite flowed downward to the population at large and were executed by the bureaucracy (Anderson, 1994) Decisions were taken at the top and there was no popular participation which, means it is only the expression of values and choices 
of the privileged who dictated their views to the masses (Howlett and Ramesh, 2003). This is an approach where policymaking leaders act in an environment which is characterized by apathy and information distortion and governs a large passive mass.

Safety was considered as an important strategy for ease of administering learner discipline. The study revealed that in some schools the Safety and Security Committee did not exist, it was never established, it was imaginary, it was thought of when incidents that sparked violence between learners had occurred; it was then that educators thought about establishing such a committee.

It was further established that in schools where the committee was established, it was dysfunctional; it did not know or perform its duties. The findings of the study reflect negligence and poor planning in the part of administration and negation of following standing procedures. Chapter 2, Bill of Rights (RSA, 1996) states that every person has the right to an environment that was not detrimental to his/her health or well being. This was also an indication that there was a difference between policy implementation and formulation. There may be some good policies but the implementers neglect them as they implement the programme according to their own understanding (Anderson, 1994).

The findings of the study contradicted Netshitaname and Van Vollenhoven (2002) and Prinsloo (2004) who are of the opinion that it is the duty of the educator to teach, to provide an educational, physical and mental safety. It is their duty as well to provide "duty of care" for learners. To look for the well being means in the school, in the classroom the educator should create a conducive atmosphere for learners by preventing any threats and nasty incidence to occur in the school premises.

\section{Conclusion}

The conclusions drawn from this study suggest that implementation of learner discipline is inundated with numerous problems such as violation of the code of conduct by some administrators as suspensions and expulsion were effected without the knowledge of the Head of Department. Some educators were not keen to implement the suggested punitive measures to offending learners for fear of losing their favour because they are afraid of them. The implementation of learner discipline was also affected by a poor safety policy implementation as some schools did not have safety plans. The conclusions that can be drawn from this study is that the schools still feel that corporal punishment is the most effective strategy for maintaining learner discipline as it is still used by schools. It was abolished without consulting with parents and learners a typical example of Top-Down approach of policy formulation. The implementations of alternatives to corporal punishment seemed not to yield good results in terms of improving learner discipline in schools. It faced problems such as lack of co-operation from educators, parents and learners themselves. The implementers of learner discipline who can be called street level bureaucrats also lacked skills for handling these alternatives to corporal punishment.

\section{Recommendatins}

The study recommends that:

- The DoE should build the capacity of SMTs, SGBs, RCL and educators on strategies to handle learner discipline.

- Educators should work as a team when they are dealing with learner discipline and constantly meet to review their strategies for implementing learner discipline.

- The researcher recommends that in the crafting of the Code of Conduct, the SGBs and SMTs should involve those parents who are literate who understand the procedures, and are able to interpret policies. The language used in the Code of Conduct should be that of school community for ease of administration.

- The study recommends that the schools should strictly adhere to the school Code of Conduct and other relevant statutes when dealing with serious acts of misconduct which deserve suspension or expulsion.

- The Safety and Security committee should be established in all schools because it is the responsibility of the educators to ensure learner safety.

\section{References}

Anderson, J.E. (1994). Public Policy-making: An introduction Boston: Houghton Mifflin. Available at http://www.amazon.com/By-JamesAnderson-Policymaking-Introduction/dp/B004HXBYFQ/ref=pd_sim_sbs_b_2. Accessed 16 March 2010.

Bray E (2005). Codes of conduct in public schools: a legal perspective. South African Journal of Education, 25:133-138. 
Charles, M.C. (2008). Building Classroom discipline (9th Ed.) Boston, M.A. Pearson/Allyn and Bacon.

Cohen, L., Manion, L. and Morrison, K. (2006). Research Methods in Education: (5 $5^{\text {th }}$ Ed.). London: Routledge Falmer.

Cresswell, J.W. (1998). Qualitative inquiry and research design: choosing amongst five traditions. Thousand Oaks, California: Sage Publications.

Department of Education (2000). Alternatives to Corporal Punishment: The learning Experience. Pretoria: Government Printer. Sol Plaatjie.

Department of Education, (2000). Guidelines for consideration of School Governing Bodies in adopting a Code of Conduct. Notice of 2000. Pretoria:Government Printers.

Hammett, D. (2008). Disrespecting teacher: The decline in social standing of teachers in Cape Town, South Africa. International Journal of Educational Development, 28:340-347.

Howlett, M. and Ramesh, J. (2003). Policy Cycles and policy subsystems. Oup, Canada

Joubert, R. and Prinsloo, S. (2001). Education Law. A Practical guide for educators. Pretoria. Natal/Sacte College.

Joubert, R., De Waal, E. and Rossouw, J.P. (2004). Discipline: Impact on access to equal educational opportunities. Perspectives in Education, 22(3), 77-78.

Lee, N. and Lings, I. (2008). Doing business research; a guide to theory and practice. London: SAGE.

Livesey, C. (2006):Revision: Sociological Methods: The Distinctions between primary and Secondary data, and between quantitative and qualitative data.

Maree, K. (ed). (2007). First Steps in Research. Pretoria: Van Schaik

Merrian, B.S. (1984). A Guide to Research for Educators and Trainers of Adults. Malabar, Fla: Krieeger Pub.co.

Mertens, D.M. (2010). Research and evaluation in education and psychology: Integrating diversity with quantitative, qualitative, and mixed methods (3rd Ed.). Thousand Oaks, CA: Sage.

Netshitaname, N.E. and Van Vollenhoven, W.J. (2002). School Safety in rural schools: Are schools safe as we think they are? South African Journal of Eduaction, 22(4), 313-318.

Paudal, N.R. (2009). A critical Account of Policy Implementation Theories: Status and Reconsideration. Vol XXV, No 2, December 2009.

Porteus, K., Vally, S. and Ruth, T. (2001). Alternatives to corporal punishment. Cape Town: Heinemann.

Prinsloo, S. (2006). Sexual harassment and violence in South African schools. South African Journal of Education. 26(2), 305-318.

Pulzl, H. and Treib, O. (2007). Chapter 7: Implementing Public Policy in Fischer, F., Miller, G.J. and Sidney, M.S. (2007) (eds). Handbook of Public Policy Analysis: theory, Politics and Methods. Boca Raton: Taylor and Francis Group.

Republic of South Africa. (1996a). The Constitution of the Republic of South Africa. Act No. 108 of 1996. Pretoria: Government Printer.

Republic of South Africa, (1996). South African Schools Act.

Roos, R. (2003). Legal requirements for school rules and disciplinary sanctions. University of Potchefstroom.

Rule, R. and John, V. (2011). Case Study Research, first edition, Van Schaik Publishers. Pretoria.

Squelch, J.M. (2000). Discipline. Pretoria: Centre for Education Law and Education.

Stevens, G., Wyngaard, G.A. and Van Niekerk, A. (2001). The Safe school Model: An Antidote to school violence. Perspective in Education, 19(2).

Sushila, B. (2004). Management and Evaluation of Schools. Oxford University Press. East Africa Limited. Kenya. Trinidad and Tobago Ministry of Education (2005) no-violent measures needed to resolve Differences and Dispute.www.TTIPS.org.

Tashakkori, A. and Teddlie, C. (2003). Handbook of mixed methods in social \& behavioural research (Eds.). Thousand Oaks, CA: Sage.

The Daily Despatch of Wednesday 10 October 2012

Wolhuter, C.C. and Steyn, S.C. (2003). Learner discipline at school: A comparative educational perspective. Koers. Bulletin for Christian scholarship. 68(4):521-538..

Yin, R.K. (2003). Case study research: Design and methods (3rd Ed.). Thousand Oaks, CA: Sage. 